\title{
A 80 MM SEPARATION OF THE SYMPHSIS PUBIS DURING VAGINAL DELIVERY
}

\author{
Paek Lee, MD¹, Euy Hyuk Kim, MD'1, Han Kook Yoon, MD² \\ Departments of ${ }^{1}$ Obstetrics and Gynecology, ${ }^{2}$ Orthopedics, National Health Insurance Corporation Ilsan Hospital, Goyang, Korea
}

Separation of the symphysis pubis during the vaginal delivery is rare, but a serious complication. Treatment is generally conservative with rest and appropriately fitted pelvic binder. But surgery may be necessary when symphyseal separation is more than $40 \mathrm{~mm}$. A case of $80 \mathrm{~mm}$ separation of symphysis pubis developed after vaginal delivery is presented with review of the literature.

Keywords: Symphysis pubis, Vaginal delivery, Separation

임신과 분만을 경험하는 산모들에게 일정 범위 안에서 발생하는 치골 결합 분리는 정상적인 해부학적 변화 과정이다. 치골 결합 분리는 치골 결합과 천장골 관절 부위의 팽창에 의해 발생하며 임신 10 주부터 증상 이 시작되어 임신 후기까지 나타난다[1]. 일반적으로 치골 결합 분리는 분만 후 4주에서 12주 내에 다시 결합하여 정상화 된다[2]. 그러나 때로 는 분만 중 태아 아두가 골반 강내로 진입하는 도중에 치골 결합이 완전 하게 분리되는 경우도 발생하며, 이런 경우에 치골 결합이 분리되면서 깨지는 소리가 들릴 수 있으며, 심한 통증이 치골 부위에서 발생하기도 한다. 치골 결합 분리의 진단은 골반 방사선 촬영 검사로 가능하며 일반 적으로 치골 결합 분리가 $10 \mathrm{~mm}$ 이상 관찰되면 진단 될 수 있고, 대부 분의 환자들은 치골 결합이 $10 \mathrm{~mm}$ 이상 분리가 나타날 때부터 증상을 느끼게 된다[3]. 질식 분만 후 치골 결합 분리의 발생률은 저자에 따라 분만 600 건 당 1 건에서부터 30,000 건 당 1건으로 다양하게 보고되고 있으나[4,5], 일반적으로 매우 드문 것으로 알려져 있다66]. 본 저자는 질 식 분만 도중 발생한 $80 \mathrm{~mm}$ 치골결합 분리의 1 예를 경험하였기에 간단 한 문헌 고찰과 함께 보고하는 바이다.

\section{증 례}

\author{
환 자: 장 $\mathrm{O}$ 희, 30 세, 초산부 \\ 주증상: 분만 도중 발생한 골반 통증 및 보행 장애 \\ 과거력: 특이 사항 없었다. \\ 산과력: 1-0-0-1
}

현병력: 임신 확인 후 산전 진찰에서 이상 소견 없었던 초임부로 키는 $152 \mathrm{~cm}$, 체중은 임신 전 $44 \mathrm{~kg}$ 에서 입원 당시 $56 \mathrm{~kg}$ 으로 측정되었다. 임신 40주에 입원하여 유도 분만을 시행하였으며 입원 당시 활력 징후 는 정상이었고, 태아 심음도 145 회/분으로 규칙적이었으며 비수축 검사
에서 반응성이 있었다. Oxytocin을 사용하여 유도 분만을 시작하였으며, 1 시간 30 분 후에 자궁경관은 $1.5 \mathrm{~cm}$ 개대되었고, 이후 자발적으로 양 막이 파수되었다. 환자는 3 시간 경과 후 2 분 간격으로 규칙적인 진통을 보이면서, 자궁 경관은 $4 \mathrm{~cm}$ 개대되었고, 진통 활성기에 진입하면서 경 막 외 마취를 시행 받았다. 유도 분만 시작하여 자궁 경관이 완전 개대 되는 분만 2 기까지 6 시간 30 분이 소요되었다. 분만 진행 제2기 시점에 서 산모의 골반부위에서 균열음이 들렸으며 분만 진행 제 2 기 45 분 경과 후 산모는 $3,700 \mathrm{~g}$ 의 남아를 분만하였으며, Apgar 점수는 1분에 8점, 5 분에 9점으로 측정되었다. 분만 도중 McRobert 수기법, 자궁 바닥 압박 법 등은 사용하지 않았다. 분만 후 2 도 열상이 질벽 전방 요도 근처에서 관찰되어 1 차 봉합을 시행하였으며 다른 합병증은 동반되지 않았다. 이 후 환자는 심한 허리 통증과 장골천골 통증을 호소하였으며, 위골반 부 위에 부종이 관찰되었고, 압통 또한 동반되었다. 분만 후 도움 없이는 서있기와 걷기가 불가능하여, 절대 침상 안정을 취하도록 하였다.

산후 1일째에 경막 외 마취 카테터는 제거하였으나, 심한 거동 불편으

Received: 2010.12.29. Accepted: 2011.2. 1.

Corresponding author: Euy Hyuk Kim, MD

Department of Obstetrics and Gynecology, National Health

Insurance Corporation Ilsan Hospital, 1232 Baekseok-dong,

Ilsandong-gu, Goyang 410-719, Korea

Tel: +82-31-900-0211 Fax: +82-31-900-0138

E-mail: raksumi10@gmail.com

This is an Open Access article distributed under the terms of the Creative Commons Attribution Non-Commercial License (http://creativecommons.org/licenses/ by-nc/3.0/) which permits unrestricted non-commercial use, distribution, and reproduction in any medium, provided the original work is properly cited.

Copyright (๑) 2011. Korean Society of Obstetrics and Gynecology 


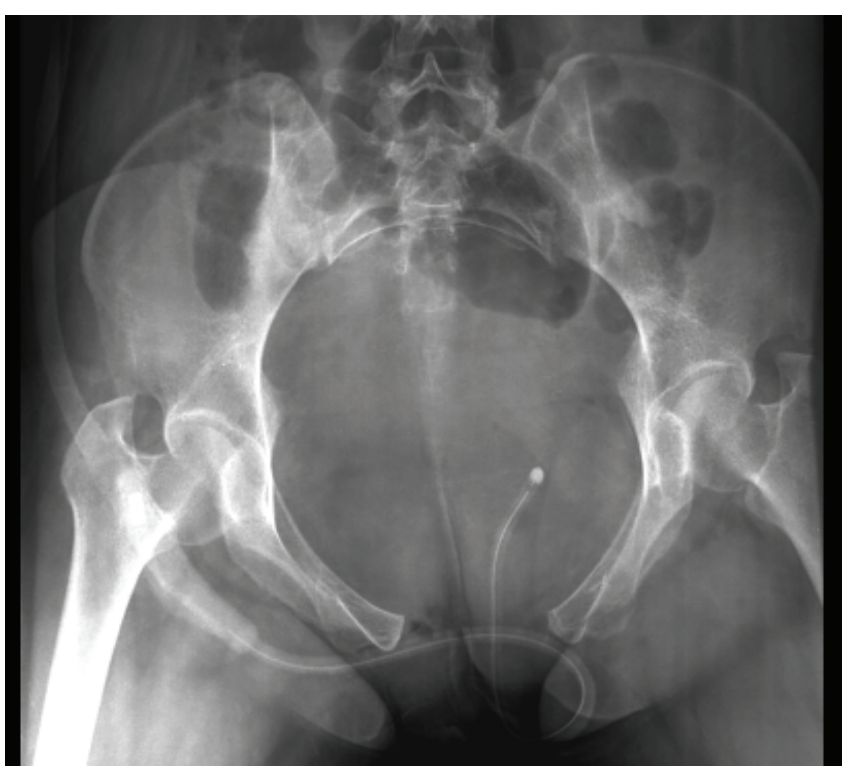

Fig. 1. A $80 \mathrm{~mm}$ separation of the symphysis pubis (5 days after vaginal delivery).

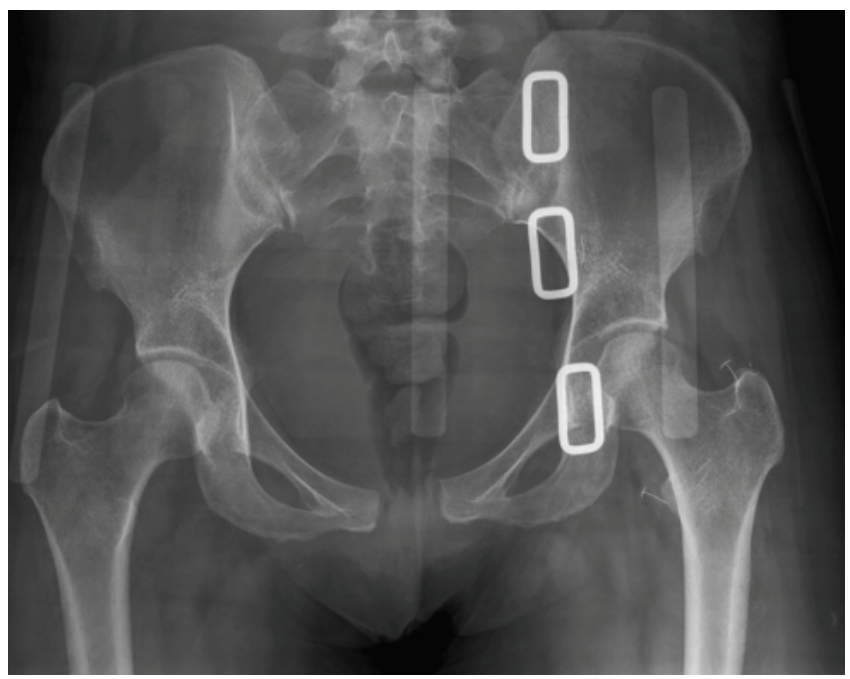

Fig. 2. After 12 days of delivery showing a $30 \mathrm{~mm}$ separation of the symphysis pubis with parts of pelvic brace.

로 인하여 요관 카테터는 제거하지 못하였다. 심한 허리 통증에 대해 진 통제를 투여하여 증상 조절을 시도하였지만, 증상 호전이 없었고, 심한 허리 통증에 대한 신체검사를 시행하였으며 위골반 부위에서 압통이 동 반되는 부종이 촉지 되었다. 환자는 분만 후 2 도 열상으로 인해 회음부 부종이 심하였고 이로 인한 통증으로 생각되어 산후 4일째까지 경과 관 찰을 유지하였으며, 증상 호전 양상이 없어 산후 5일째에 골반 전후 방 사선 촬영 검사에서 $80 \mathrm{~mm}$ 의 치골 결합 분리를 관찰하여(Fig. 1) 환자 는 본원 산부인과로 전원 되었으며 기본적 검사 후 분만 중 치골 별합 분리 진단 하에 정형외과에 협진 의뢰되었다.

환자는 본원에서 분만 중 치골 결합 분리 진단 하에 정형외과에

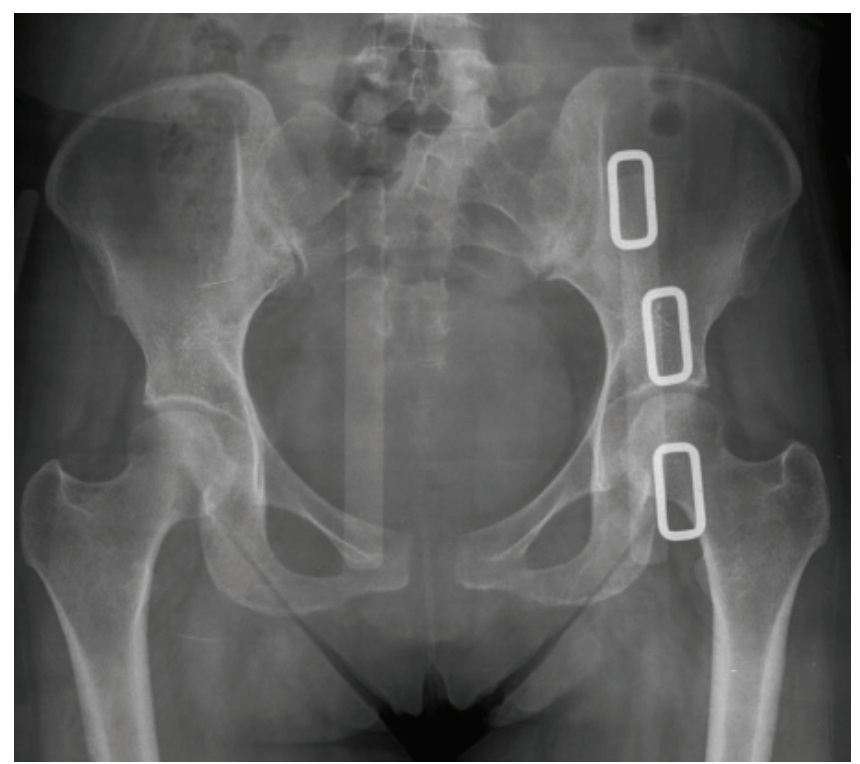

Fig. 3. At readmission, after 35 days of delivery showing a $20 \mathrm{~mm}$ separation of the symphysis pubis with parts of pelvic brace.

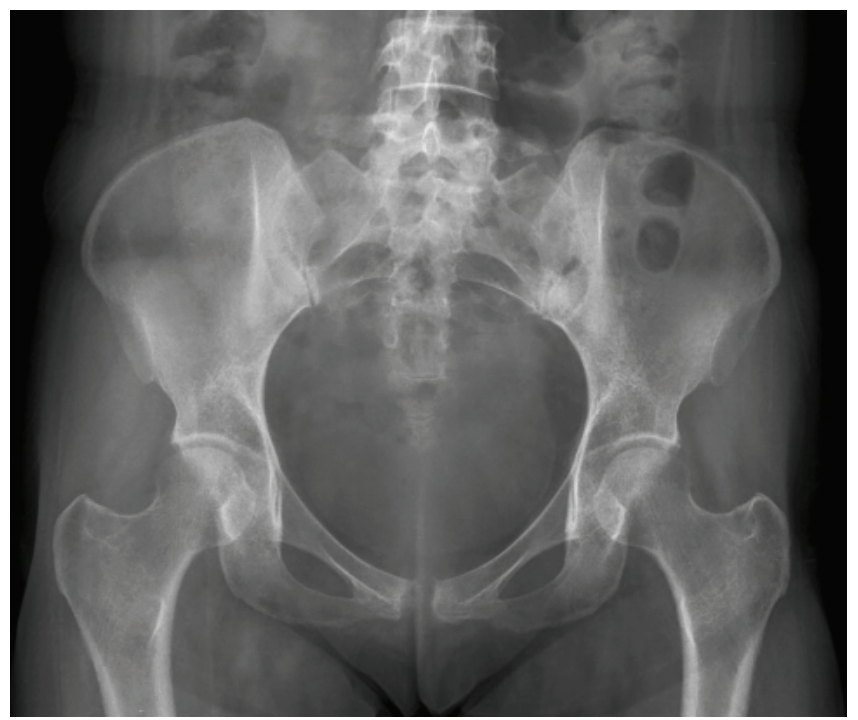

Fig. 4. After 6 months of delivery showing without any instrument.

서 골반 복대(pelvic blinder)를 착용하였다. 1주일 동안 절대 침상 안 정을 취하면서 바로 누운 자세에서 골반걸이(pelvic sling)를 착용하고 hammock 견인을 취하였다. 총 견인 무게는 $20 \mathrm{lbs}($ 약 $9 \mathrm{~kg}$ )로, 좌우 대 칭적으로 각각 $10 \mathrm{lbs}$ 로 나눠서 견인을 시행하였다. 보존적 치료 시행 3 주 후, 치골 결합 부위의 분리는 $30 \mathrm{~mm}$ 으로 감소 되었으며, 환자는 골 반 고정기를 착용한 상태에서 앉기, 걷기 등이 가능하였다(Fig. 2). 환자 는 골반 복대(pelvic blinder)를 착용한 상태에서 바로 누운 자세를 유지 하여 보존적 치료를 하였다. 보존적 치료를 지속하는 동안 압박에 의한 궤양을 예방하기 위해 정기적으로 체위를 변경해 주었다. 물리 치료는 산후 14 일째부터 시작하였으며, 처음 시작 시 환자는 보행 보조기 없이 


\section{KOREAN JOURNAL OF OBSTETRICS \& GYNECOLOGY}

Paek Lee, et al. Symphysis pubis, vaginal delivery

는 걸을 수가 없었고 산후 15 일째까지는 하지를 움직일 때 통증이 동반 되었으나 이후 증상 호전되어 산후 28일째 퇴원하였다. 그러나 퇴원 1 주일 후 위골반 통증 재발되어 산후 36 일째 재입원하였다. 재입원 당시 골반 전후 방사선 촬영 사진에서 치골 결합 부위에 $20 \mathrm{~mm}$ 정도의 분리 소견이 지속적으로 관찰되었다(Fig. 3). 환자는 분만 4개월 후까지도 보 행 시 경미한 통증을 호소하였으며 분만 6 개월이 되어서야 골반 전후 방사선 촬영 사진에서 치골 결합 분리가 $10 \mathrm{~mm}$ 미만으로 감소하였고, 다른 증상도 소실 되었다(Fig. 4). 이후 외래에서 특이 소견 없이 정기적 으로 경과를 추적 관찰하였다.

\section{고 찰}

치골 결합은 임신, 분만 도중에 현저한 해부학적 변화가 일어난다. 임 신과 관련된 병태적인 골반 통증을 호소하는 환자들의 치골 관절의 분 리 정도를 보다 정확하게 평가하고 적절한 치료 방침을 정하기 위해서 는 여성들의 임신과 관련된 치골 결합 관절의 분리 간격의 생리적인 변 화를 정확하게 이해하고 이에 대한 적절한 치료를 시행하는 것이 중요 하다.

Wurdinger 등[1]은 임신을 경험하지 않은 여성들보다 임신 및 출산을 경험한 여성들의 치골 결합 간격이 통계학적으로 유의하게 넓다는 것을 보고하였다. Bahlmann 등[7]이 211명의 여성들을 대상으로 연구한 결 과에 따르면, 초산모의 $56 \%$ 에서 치골 결합 부위의 간격이 임신 8주 때 에는 평균 $4 \mathrm{~mm}$ 이나, 임신 후반기에는 평균 $7 \mathrm{~mm}$ 정도로 늘어나는 소 견을 보였다. 병적인 치골 결합의 분리는 골반 방사선 촬영 사진으로 진 단하며, 10-13 mm 이상 치골 결합 분리가 발생했을 때 진단되며[8], 임 상적으로 분리 부위의 촉지나 분리 시에 발생하는 튕기는 소리 등을 통 해 추정할 수도 있다[9]. 치골 결합 부위가 $10 \mathrm{~mm}$ 이상 분리가 일어나 게 되면, 산모들이 통증 등의 증상을 호소하기 시작하며, $60 \mathrm{~mm}$ 이상 치골 결합 부위의 분리가 일어나면 천골 장골 관절에까지 병태적인 증 상이 발생하게 된다[10].

본 증례의 경우 치골 결합 혹은 천골장골 연골 결합의 분리는 분만 도 중 발생한 과도한 고관절 외전으로 인한 치골 결합의 심한 손상에 의해 발생했다고 볼 수 있겠지만 이외에 다른 요인들도 함께 고려해야 한다. 기존 연구에 따르면 치골 결합 분리의 원인으로 생각되는 것들은, 이전 의 치골 결합 분리의 과거력, 진행이 힘들었던 분만력, 태아 아두 골반 불균형, 비정상적인 태아의 태위, 이전의 골반 외상 병력, 경막 외 마취 및 McRobert 수기법을 이용한 분만 과정 등이 있다[5,11,12]. 그러나 산 모의 연령, 출산력, 태아 몸무게, 임상적 골반 계측과는 뚜렷한 연관성이 없다고 보고되고 있다[13].

임상적으로 치골 결합 분리와 동반되는 증상들은 치골 부위의 심한 통증과 분만 시 튕기는 소리, 동요성 보행, 천골장골과 위골반 부위의 심한 통증 등이 있으며[5], 환자들은 서 있거나 허리를 구부리는 자세 등을 취하는 것이 힘들게 된다. 종종 다리를 들어올리는 행동이 허벅지 앞, 뒤로 방사통을 유발할 수도 있다[3].
증상이 있는 치골 결합 분리의 치료는 대부분 비수술적 치료를 한다. 보통 측와위를 한 상태에서 침상 안정을 하거나, 진통제 혹은 골반 복대 를 착용하는 것이 회복에 도움을 준다. 대부분의 산모에서는 분만 6 주 에서 8주 내에 증상의 소실이 있으며, 이보다 길게 지속하는 경우 만성 적인 형태로 생각되는 치골염으로 진단할 수 있으며 이를 예방하거나 조기에 진단하기 위해서는 증상이 소실된 이후에도 지속적인 추적 관찰 이 필요하다. 치골 결합 분리가 $40 \mathrm{~mm}$ 이상으로 심한 경우에 수술이 필 요할 수도 있지만 최근 연구 결과에 따르면 보존적 치료가 대부분의 경 우 좋은 결과를 보인다고 보고되고 있다[10]. 수술은 치골 결합 분리가 재발된 경우와 골반 통증, 보행 장애 증상 등이 소실되지 않고 지속되는 경우에 한하여 시행하며, 단지 골반 결합이 불안정 하다고 해서 수술이 추천되지는 않는다[5,14].

한편 이전에 치골 결합 분리를 질식 분만에서 경험한 경우 다음 임신 에서 재발률은 $50 \%$ 이상으로 높게 보고하고 있기 때문에 제왕 절개를 고려할 것을 추천하고 있다[15].

본 증례의 경우에는 $80 \mathrm{~mm}$ 의 분리가 일어났으며 증상이 재발하였음 에도 수술적 치료 없이 골반 복대 및 침상 안정 등의 보존적 치료로 환 자를 성공적으로 치료할 수 있었다.

최근 질식분만에 대한 산부인과 의료진의 관심이 높아지고 질식분만 의 장점에 대한 국민적 인식 역시 높아짐에 따라 분만에서 질식 분만이 차지하는 비중이 점점 높아지고 있는 것이 사실이다. 이런 사회적 상황 에 발맞춰 치골 결합 분리와 같은 질식 분만과 관련된 합병증에 대한 적 절한 예측과 치료에 관하여 특징적인 임상적 증상을 숙지하고, 치골 결 합 관절 분리의 발생 가능성을 생각하여, 분만 전후에 조기 진단을 할 수 있다면, 분만 후 산모에 대한 적절하고 신속한 치료를 시행할 수 있 고 그 후유증을 최소화 할 수 있을 것으로 생각된다.

비록 논란의 여지가 있지만 질식 분만 후 발생한 심각한 치골 결합 분 리는 수술 없이 보존적 치료만으로 호전 될 수 있으며, 분만을 기점으로 해서 그 전후에 발생한 치골 부위의 통증 및 보행 장애 증상이 있을 시 에는 골반 관절 결합 분리의 진단 및 감별진단을 위해 골반 방사선촬영 검사가 필요하다. 이후에 환자의 지속적인 경과관찰도 중요하며, 이에 본원에서는 질식분만 도중 발생한 $80 \mathrm{~mm}$ 치골 결합 분리의 1 예를 경험 하여 경과 관찰하였기에 간단한 문헌 고찰과 함께 보고하는 바이다.

\section{References}

1. Wurdinger S, Humbsch K, Reichenbach JR, Peiker G, Seewald HJ, Kaiser WA. MRI of the pelvic ring joints postpartum: normal and pathological findings. J Magn Reson Imaging 2002;15:324-9.

2. Snow RE, Neubert AG. Peripartum pubic symphysis separation: a case series and review of the literature. Obstet Gynecol Surv 1997:52:438-43.

3. Brehm W, Weirauk HV. Separation of the symphysis pubis dur- 
ing labor. Am J Obstet Gynecol 1928;15:187-91.

4. Taylor RN, Sonson RD. Separation of the pubic symphysis. An underrecognized peripartum complication. J Reprod Med 1986;31:203-6.

5. Reis RA, Baer JL, Arens RA, Stewart E. Traumatic separation of the symphysis pubis during spontaneous labor. Surg Gynecol Obstet 1932;55:336-54.

6. Cunningham FG, Leveno KJ, Bloom SL, Hauth JC, Rouse DJ, Spong CY. Williams obstetrics. 23rd ed. New York: McGrawHill Medical; 2010.

7. Bahlmann F, Merz E, Macchiella D, Weber G. Ultrasound imaging of the symphysis fissure for evaluating damage to the symphysis in pregnancy and postpartum. Z Geburtshilfe Perinatol 1993; 197:27-30.

8. Heyman J, Lundqvist $A$. The symphysis pubis in pregnancy and parturition. Acta Obstet Gynecol Scand 1932;12:191-226.

9. Dhar S, Anderton JM. Rupture of the symphysis pubis during labor. Clin Orthop Relat Res 1992;(283):252-7.
10. Kharrazi FD, Rodgers WB, Kennedy JG, Lhowe DW. Parturitioninduced pelvic dislocation: a report of four cases. J Orthop Trauma 1997;11:277-81.

11. Cappiello GA, Oliver BC. Rupture of symphysis pubis caused by forceful and excessive abduction of the thighs with labor epidural anesthesia. J Fla Med Assoc 1995;82:261-3.

12. Heath T, Gherman RB. Symphyseal separation, sacroiliac joint dislocation and transient lateral femoral cutaneous neuropathy associated with McRoberts' maneuver: a case report. J Reprod Med 1999;44:902-4.

13. Musumeci R, Villa E. Symphysis pubis separation during vaginal delivery with epidural anesthesia: case report. Reg Anesth 1994;19:289-91.

14. Hagen R. Pelvic girdle relaxation from an orthopaedic point of view. Acta Orthop Scand 1974;45:550-63.

15. Culligan $P$, Hill $S$, Heit M. Rupture of the symphysis pubis during vaginal delivery followed by two subsequent uneventful pregnancies. Obstet Gynecol 2002;100:1114-7.

\section{질식 분만 도중 발생한 $80 \mathrm{~mm}$ 치골 결합 분리의 1 예}

\section{국민건강보험공단 일산병원 ${ }^{1}$ 산부인과, ${ }^{2}$ 정형외과}

이 백, 김의혁, 윤한국 ${ }^{2}$

질식 분만 시 치골 결합 분리는 매우 드물지만 심각한 부작용이다. 치료는 일반적으로 골반 보조기를 사용하며 안정을 취하는 보존적으로 한다. 그러나 치골 결합이 $40 \mathrm{~mm}$ 이상 분리 되었을 경우 수술이 필요할 수 있다. 저자들은 질식 분만 도중 발생한 $80 \mathrm{~mm}$ 치골결합 분리 의 1 예를 경험하였기에 간단한 문헌 고찰과 함께 보고하는 바이다.

중심단어: 치골, 질식 분만, 분리 